\title{
The use of gadolinium as a burnable poison within U3Si2 fuel pellets
}

DOI:

10.1016/j.jnucmat.2018.06.044

\section{Document Version}

Accepted author manuscript

Link to publication record in Manchester Research Explorer

\section{Citation for published version (APA):}

Turner, J., Buckley, J., Philips, G., \& Abram, T. (2018). The use of gadolinium as a burnable poison within $\mathrm{U}_{3} \mathrm{Si}_{2}$ fuel pellets. Journal of Nuclear Materials, 509, 204-211. https://doi.org/10.1016/j.jnucmat.2018.06.044

\section{Published in:}

Journal of Nuclear Materials

\section{Citing this paper}

Please note that where the full-text provided on Manchester Research Explorer is the Author Accepted Manuscript or Proof version this may differ from the final Published version. If citing, it is advised that you check and use the publisher's definitive version.

\section{General rights}

Copyright and moral rights for the publications made accessible in the Research Explorer are retained by the authors and/or other copyright owners and it is a condition of accessing publications that users recognise and abide by the legal requirements associated with these rights.

\section{Takedown policy}

If you believe that this document breaches copyright please refer to the University of Manchester's Takedown Procedures [http://man.ac.uk/04Y6Bo] or contact uml.scholarlycommunications@manchester.ac.uk providing relevant details, so we can investigate your claim.

\section{OPEN ACCESS}




\section{Accepted Manuscript}

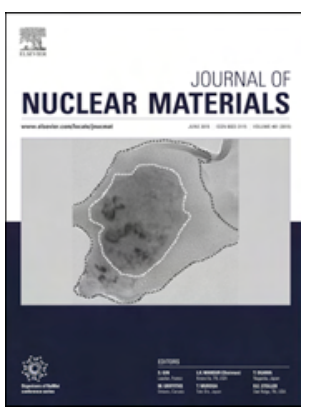

The use of gadolinium as a burnable poison within $\mathrm{U}_{3} \mathrm{Si}_{2}$ fuel pellets

J. Turner, J. Buckley, G. Philips, T.J. Abram

PII: $\quad$ S0022-3115(18)30580-4

DOI: $\quad$ 10.1016/j.jnucmat.2018.06.044

Reference: NUMA 51057

To appear in: Journal of Nuclear Materials

Received Date: 23 April 2018

Revised Date: 1 June 2018

Accepted Date: 28 June 2018

Please cite this article as: J. Turner, J. Buckley, G. Philips, T.J. Abram, The use of gadolinium as a burnable poison within $\mathrm{U}_{3} \mathrm{Si}_{2}$ fuel pellets, Journal of Nuclear Materials (2018), doi: 10.1016/ j.jnucmat.2018.06.044.

This is a PDF file of an unedited manuscript that has been accepted for publication. As a service to our customers we are providing this early version of the manuscript. The manuscript will undergo copyediting, typesetting, and review of the resulting proof before it is published in its final form. Please note that during the production process errors may be discovered which could affect the content, and all legal disclaimers that apply to the journal pertain. 


\title{
The Use of Gadolinium as a Burnable Poison within $\mathrm{U}_{3} \mathrm{Si}_{2}$ Fuel Pellets
}

\author{
Turner, J, Buckley, J, Philips, G, Abram, T.J.
}

Nuclear Fuel Centre of Excellence, The University of Manchester, United Kingdom

\begin{abstract}
Gadolinium was mixed with uranium silicide in order to investigate the potential for its use as a burnable poison with a future Accident Tolerant Fuel (ATF) system. Three methods of manufacture were investigated, including two arc melting methods and powder blending. All methods failed to produce structurally robust pellets and were seen to produce inhomogeneous material consisting of multiple silicide phases. Of particular concern was the observation of uranium metal and $(\mathrm{U}, \mathrm{Gd}) \mathrm{O}_{2}$ phases within the final material.
\end{abstract}

Keywords: Nuclear, Accident Tolerant Fuel, Burnable Poison

\section{Introduction}

Uranium silicide, specifically $\mathrm{U}_{3} \mathrm{Si}_{2}$, has been the focus of recent research as it forms a key part of a leading Accident Tolerant Fuel (ATF) candidate system (in conjunction with silicon carbide cladding) [1]. The proposed system could be tolerant to a Fukushima-type event with a significantly reduced possibility of hydrogen production.

The use of uranium silicide fuels brings a number of challenges, many of which are being explored in current research. These include manufacture [1,2], thermal performance [3] and irradiation response $[4,5]$. In order to be commercially viable in current plant designs, several further challenges must be addressed. These include a need to determine if performance improvements employed with $\mathrm{UO}_{2}$ fuel are viable with silicide-based fuels. Examples might include the use of grain growth dopants to enhance fission product retention, or burnable poison integration which is the focus of the present work.

Burnable poisons are crucial to the commercial operation of modern nuclear power plants. They greatly extend cycle lengths and hence reduce required outages by acting to flatten the neutron flux over the cycle length and spatially across the core. As a burnable poison, gadolinum has a significant advantages over alternatives; it provides the ability for engineers to independently tune both the initial burn-off rate of the poison and the total negative reactivity introduced [6]. Within many commercial plants, $\mathrm{UO}_{2}$ and gadolinia $\left(\mathrm{Gd}_{2} \mathrm{O}_{3}\right)$ are co-blended prior to sintering. The $(\mathrm{U}, \mathrm{Gd}) \mathrm{O}_{2}$ pellet shows some variation from $\mathrm{UO}_{2}$ fuel performance, but has been successful enough to see commonplace commercial service around the world [6].

It is by no means assured that gadolinium can be successfully introduced at the required concentrations within $\mathrm{U}_{3} \mathrm{Si}_{2}$ fuel pellets $(5-12 \mathrm{wt} \%)$. The gadolinium-silicon phase diagram is relatively poorly understood, and extremely limited work exists on the gadolinium-uranium phase diagram. 


\section{Methodology}

Gadolinium-doped uranium silicide pellets were produced through three methods; co-melting gadolinium metal and silicon with uranium silicide (Co-Melting route), pre-melting gadolinium and silicon to form gadolinium silicide prior to melting with uranium silicide (Pre-Melting route) and blending uranium silicide and gadolinium silicide powders prior to pellet sintering (Powder Blending route). Prior to sintering all work was completed within an inert atmosphere glove box unless otherwise stated, with atmospheres controlled below $1 \mathrm{ppm}_{2}$ and $1 \mathrm{ppm}_{2} \mathrm{O}$.

Uranium silicide material was manufactured via arc melting (Centorr 5SA Arc Furnace, contained with an inert atmosphere glove box) uranium and silicon pieces in the appropriate weight percentages to form $\mathrm{U}_{3} \mathrm{Si}_{2}$. Phase purity was confirmed prior to the introduction of gadolinium using X-ray diffraction. Ingots were flipped and re-melted 5 times to ensure sample homogeneity.

Pellets were produced from the as-melted material by comminuting to powder using a planetary ball mill (Retsch PBM 100) with tungsten carbide milling media. Where neccesary, large pieces were crushed using an agate pestle and mortar prior to milling. Following powder cominution, powders were presse and then vacuum sintered at $1500 \pm 10^{\circ} \mathrm{C}$ for 2 hours in an R.D. Webb 'Red Devil' graphite-lined vacuum furnace. Ramp rates were controlled during temperature increase to $20^{\circ} \mathrm{C} / \mathrm{min}$ and the furnace was allowed to cool naturally following a two hour hold at temperature.

Both the as-melted, milled and sintered material were characterised for microstructure and phase purity using electron microscopy and powder X-ray diffraction (XRD), with Electron Dispersion X-ray (EDX) imaging used to quantify the location and distribution of identified phases.

\section{Results}

\subsection{Arc melting}

In both Co-Melted and Pre-Melted samples, sufficient silicon was added alongside 5wt $\%$ gadolinium to maintain the ratio of metal to silcon (60:40at\%) within the material. Samples were flipped and re-melted five times in all cases to improve homogeneity. Materials produced through arc melting were investigated directly following melting for phase composition and gadolinium distribution.

Prior to combination with uranium silicide, the Pre-Melting route invovled the production of gadolinium silicide via arc melting. $\mathrm{Gd}_{3} \mathrm{Si}_{2}$ does not exist, and instead at 40 at\% $\mathrm{Si}$, a mixture of $\mathrm{Gd}_{5} \mathrm{Si}_{3}$ and $\mathrm{Gd}_{5} \mathrm{Si}_{4}$ is expected (Figure 1), which was confirmed via XRD analysis.

During arc melting of separate $\mathrm{Gd}, \mathrm{Si}$ and $\mathrm{U}_{3} \mathrm{Si}_{2}$ materials (Co-Melting route) around $5 \mathrm{wt} \%$ of the material was seen to separate from the main bulk ingot and form individual spheres and flakes. EDX investigation of these fragments reveals around half are a uranium-gadolinium alloy, occasionally containing small amounts of silicon. A number of other fragments were seen to contain small quantities $(<2 \mathrm{at} \%)$ of expected impurities - aluminium (used to manufacture a grinding jig for the preparation of uranium metal prior to $\mathrm{U}_{3} \mathrm{Si}_{2}$ manufacture), copper (used to fabricate the arc melting hearth) and tungsten (from which the arc melting electrode is made). These also typically contained a high fraction of oxygen (up to around 50at\%) and relatively small amounts of uranium.

Fragments removed following the Pre-Melting route showed similar behaviour during the melt, but were largely of a different composition containing large amounts of oxygen, 4-5at\% gadolinium, 50-60at\% uranium and up to around 20at\% silicon alongside small regions containing a number of contaminants. The preponderance of oxygen and trace amounts of unusual 


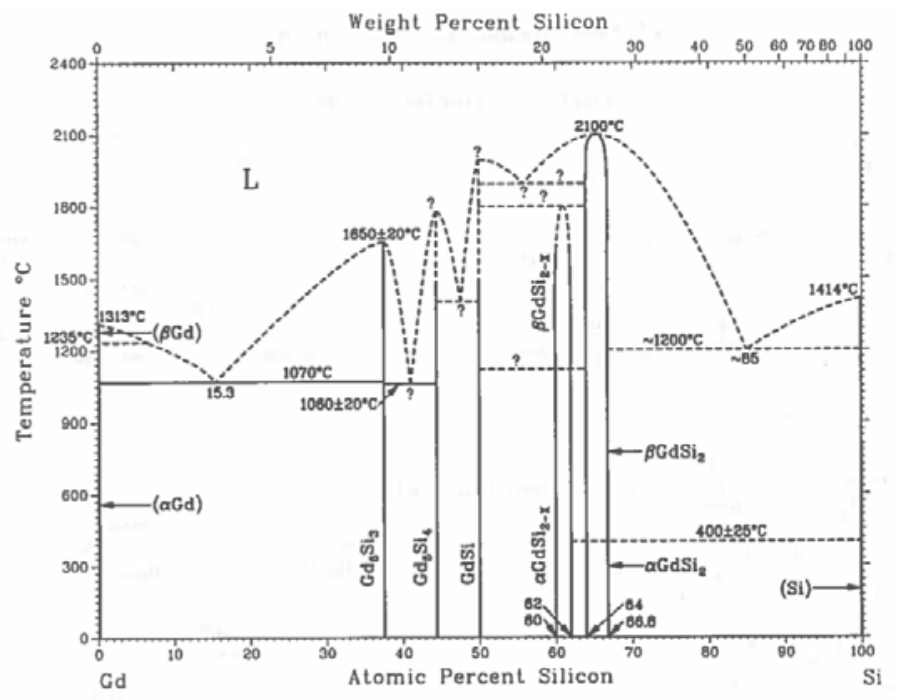

Figure 1: Gadolinium-silicon phase diagram, reproduced from [7]

contaminants (calcium, manganese, zinc) in these fragments suggests that, they may result from compounds forming which are not soluble within the bulk.

Figures 2, 3, 4 and 5 show both fabrication routes have produced a material which broadly consists of three phases; uranium metal with around $5 \mathrm{at} \% \mathrm{Gd}, \mathrm{U}_{3} \mathrm{Si}_{2}$ containing $4-5 \mathrm{at} \% \mathrm{Gd}$ and a USi phase containing 7-8at\% Gd. In the "Pre-Melt" material (Figure 3) the gadolinium and silicon rich regions closely align, as might be expected as both elements were added as a single compound. In the Co-Melt material (Figure 5) the alignment is less clear but still appears, strongly suggesting that the formation of uranium metal regions may result from the affinity of gadolinium to silicon, reducing the original $\mathrm{U}_{3} \mathrm{Si}_{2}$ material when molten. Within both materials the location of oxygen is closely related to porosity, suggesting that it is a result of sample preparation rather than a distinct oxide phase.

Phase identification was confirmed via XRD of the as-melted material, which agrees well with the EDX data (Figure 6). This shows $\mathrm{U}_{3} \mathrm{Si}_{2}$, U and USi. No gadolinium peaks were identified via XRD, but those $\mathrm{U}_{3} \mathrm{Si}_{2}$ peaks which contain some componenent of the $(0,0,1)$ direction have undergone a peak shift relative to the starting material, suggesting the $\mathrm{U}_{3} \mathrm{Si}_{2}$ lattice has been distorted predominantly in this direction. The [001] plane is the densest within the $\mathrm{U}_{3} \mathrm{Si}_{2}$ molecule, providing the greatest opportunity for the accomodation of gadolinium at uranium sites and so this agrees well with the concept of gadolinium occupying existing lattice sites.

Both Pre-Melted and Co-Melted material show a similar phase distribution; approximately $20 \% \mathrm{U}, 30 \% \mathrm{USi}$ and $50 \% \mathrm{U}_{3} \mathrm{Si}_{2}$ via Rietveld refinement of XRD for Co-Melted, and $10 \% \mathrm{U}$, $30 \% \mathrm{USi}$ and $60 \% \mathrm{U}_{3} \mathrm{Si}_{2}$ for Pre-Melted material. The slight increase in $\mathrm{U}_{3} \mathrm{Si}_{2}$ content within the Pre-Melted material suggests that the formation of a metallic uranium phase does not result from the interim formation of a gadolinium silicide phase. 


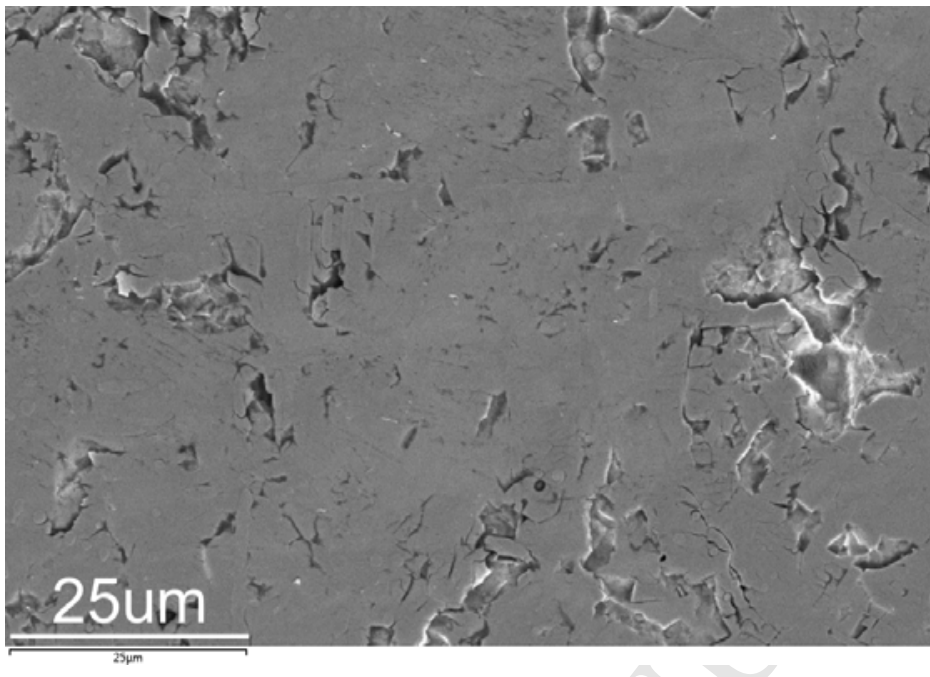

Figure 2: Electron image of pre-melted sample
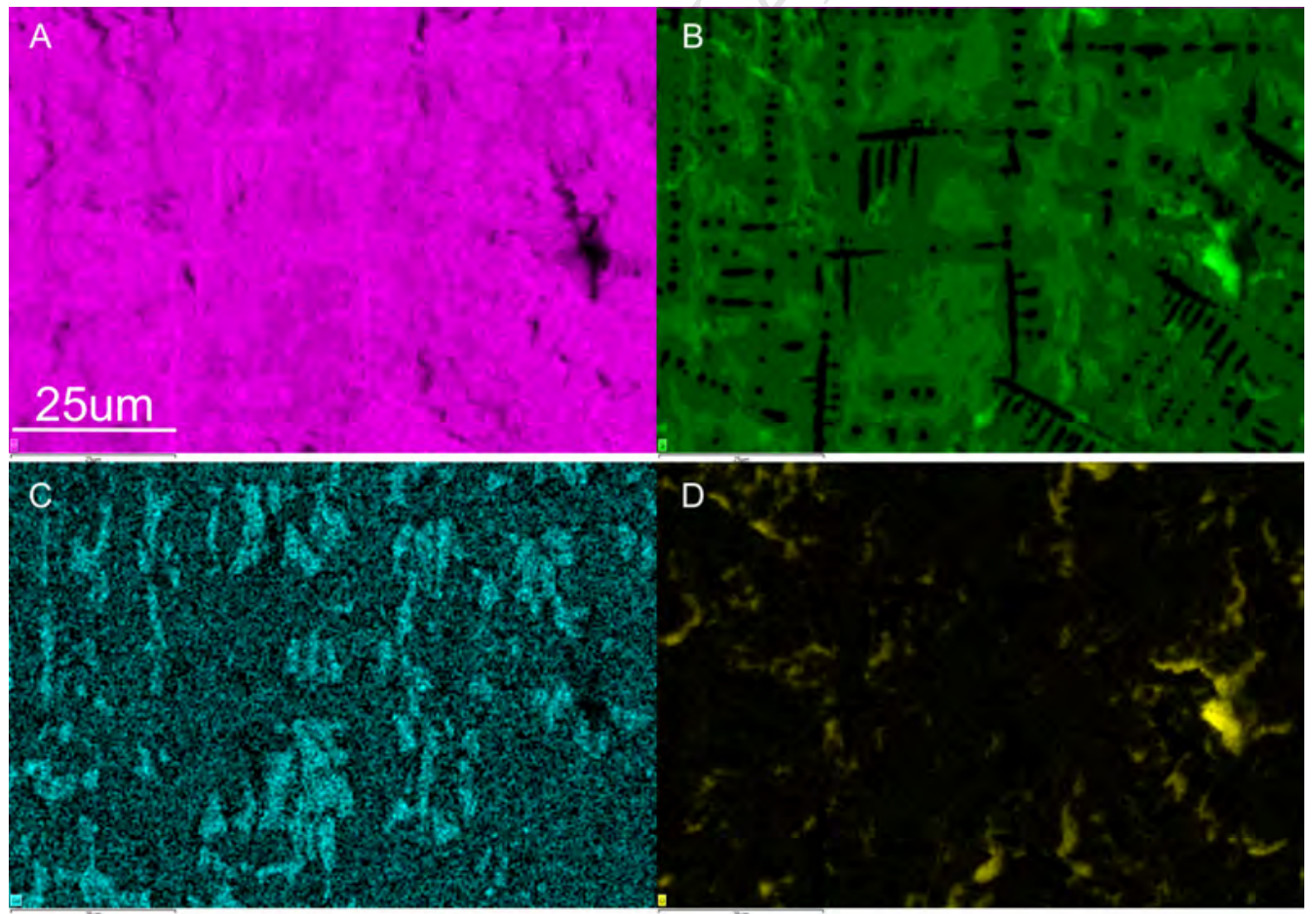

Figure 3: EDX maps of pre-melted sample. A/pink - uranium, B/green - silicon, C/blue - gadolinium. D/yellow - oxygen. Gadolinum and silicon rich regions are more closely aligned than with the co-melted sample 


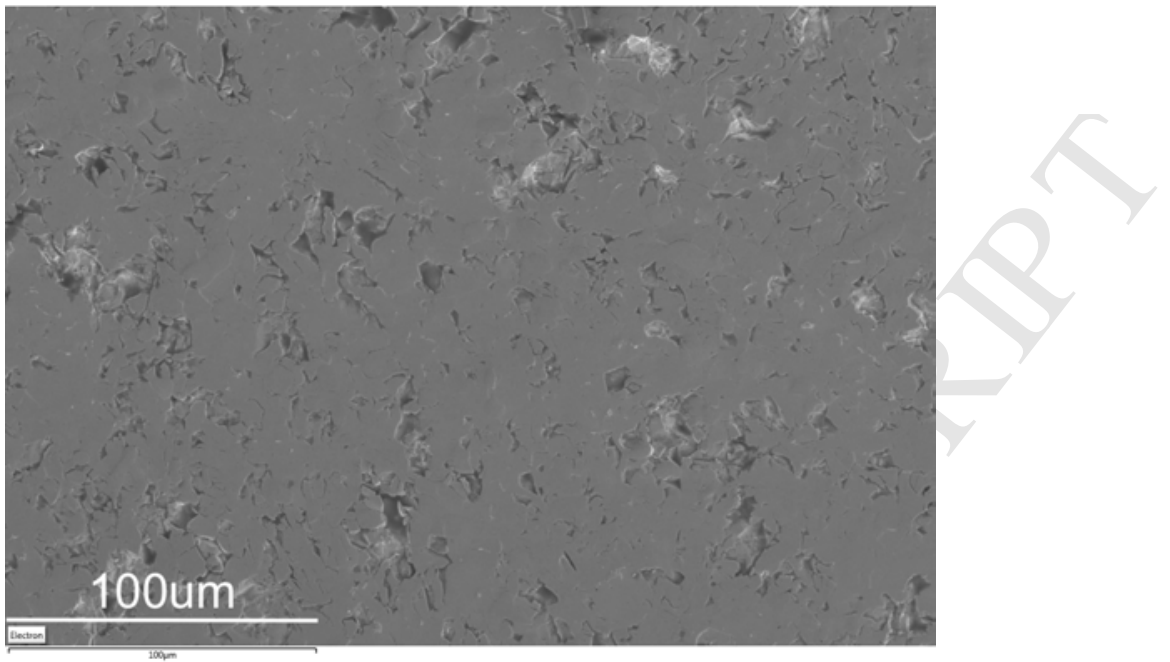

Figure 4: Electron image of co-melted sample. As expected, significant porosity and cracks are visible throguhout the image.

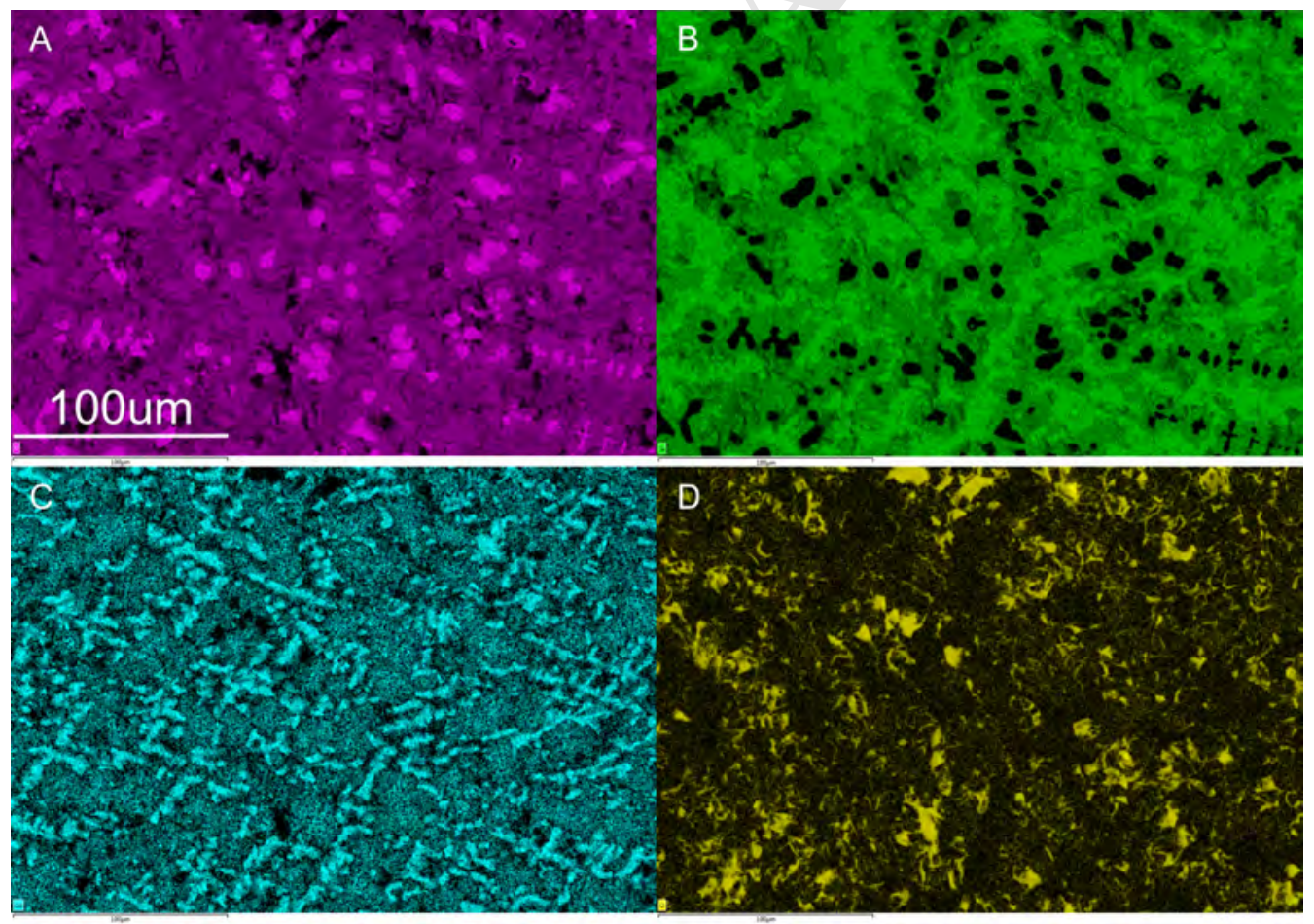

Figure 5: EDX maps of co-melted sample. A/pink - uranium, B/green - silicon, C/blue - gadolinium. D/yellow - oxygen. There are regions of depleted silicon corresponding to regions of uranium metal areas as well as silicon rich regions containing uranium and gadolinium areas. 


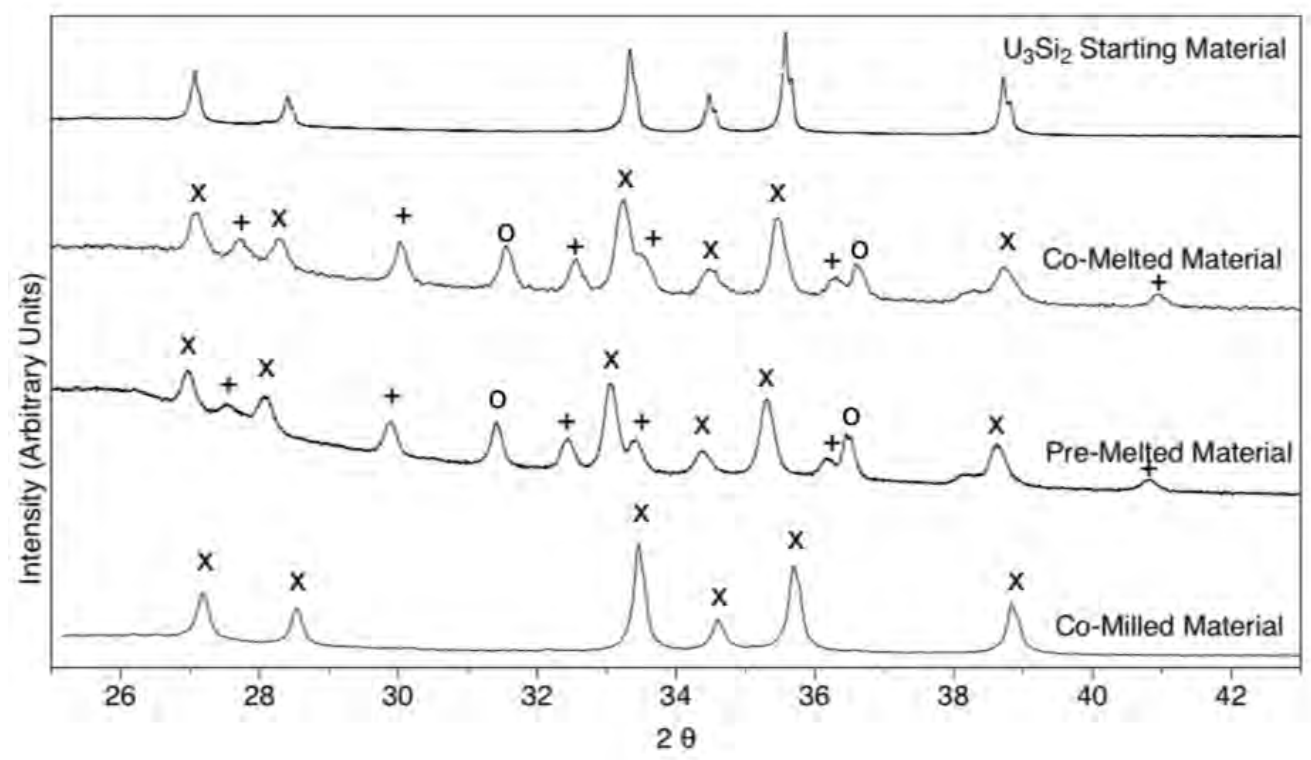

Figure 6: XRD patterns of originial $\mathrm{U}_{3} \mathrm{Si}_{2}(\mathrm{X})$ and arc-melted materials. USi (+) and $\mathrm{U}(\mathrm{o})$ phases are present in both arc-melted materials, while the original $\mathrm{U}_{3} \mathrm{Si}_{2}$ shows good phase purity

\section{3.2. Pelletisation}

In line with typical $\mathrm{U}_{3} \mathrm{Si}_{2}$ pellet manufacture, arc melted material was cominuted to powder, pressed and sintered. $\mathrm{U}_{3} \mathrm{Si}_{2}$-Gd-Si blends were initially crushed using an agate pestle and mortar within an argon atmosphere $\left(<1 \mathrm{ppm} \mathrm{O}_{2},<1 \mathrm{ppm} \mathrm{H}_{2} \mathrm{O}\right)$ before planetary ball milling for 1 hour at 300rpm. A tungsten carbide vessel was used, which was hermetically sealed within an argon atmosphere to prevent powder oxidation.

Milled powder was examined via XRD and SEM and seen to consist of a wide range of particulate, predominantly small crystalites around $1-5 \mu \mathrm{m}$ in diameter but with significant agglomerates much larger, up to $100 \mu \mathrm{m}$ (Figure 7). These agglomerates appear to have formed as a result of powder adhering to the walls of the milling vessel which was seen to be significant. Agglomerates and large particulates are clearly visible in each image within Figure 7, including non-gadolinium-doped $\mathrm{U}_{3} \mathrm{Si}_{2}$ powder. Figure $7 \mathrm{~B}$ and $\mathrm{C}$ show a large number of small crystalites which appear to coat the larger particles, which are not present in either the $\mathrm{U}_{3} \mathrm{Si}_{2}$ powder (A) or the powder produced by blending $\mathrm{U}_{3} \mathrm{Si}_{2}$ powder with Gd-Si particulate (D).

Milled powder was very similar in XRD pattern to the arc-melted materials shown in Figure 6. No specific gadolinium peaks, conversion to oxide phases, or introduction of significant tungsten contamination were observed, although trace amounts of tungsten were detected via EDX. 109 In order to prevent oxidation of the powder during XRD an air exclusion device was used, which has been seen to prevent oxidation of $\mathrm{U}_{3} \mathrm{Si}_{2}$ powders for multiple days.

Although significant oxygen was seen via EDX on the milled powder (up to around 50at $\%$ at points) this can be ascribed to a passivation layer forming on the powder surface during sample preparation rather than a bulk conversion of the silicide to oxide. $\mathrm{In}_{3} \mathrm{Si}_{2}$ the passivation layer is preferentially sampled as a result of its presence on the sample surface and the highly absorbing nature of the bulk sample. As no oxide patterns were observed via XRD analysis it is concluded 


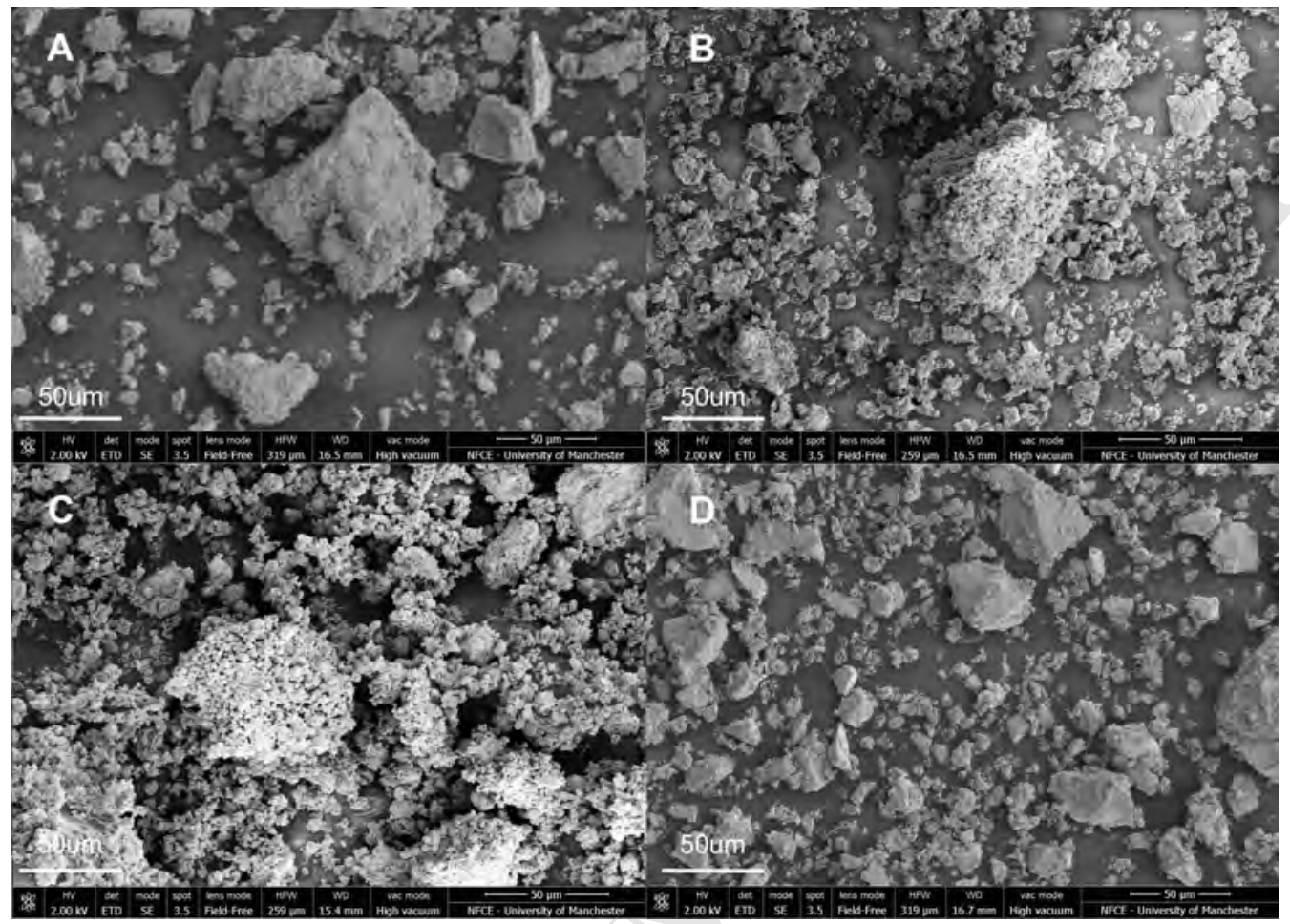

Figure 7: Electron microscopy images of powders used for pelletisation. A: $\mathrm{U}_{3} \mathrm{Si}_{2}$ powder. B: Co-Melted. C: Pre-Melted. D: Powder Blended

that no crystaline oxide phases are present in bulk within the powder.

Powders were pressed in a mechanical press with a die of $11.3 \mathrm{~mm}$ diameter with $300 \mathrm{MPa}$ of pressure. A small amount of hold-down force was applied as the pellet was removed from the die to reduce the chance of pellet fracture. Pellets were pressed as thin discs (1-2mm thick) and both Pre-Melted and Co-Melted powders prouduced robust green pellets which showed no visible defects.

\subsection{Powder Blending Route}

For powder blending, $\mathrm{U}_{3} \mathrm{Si}_{2}$ powder was produced via planetary ball milling as described above. Gd-Si powder was produced by grinding arc melting gadolinium and silicon using a pestle and mortar within an argon atmosphere, and added to $\mathrm{U}_{3} \mathrm{Si}_{2}$ to produce a final pellet with $5 \mathrm{wt} \% \mathrm{Gd}$. Powder was blended within a mixer mill (Retsch MM200) for one hour at 5Hz, with a single $5 \mathrm{~mm}$ steel ball used to remove material adhered to the vessel. The powder produced was seen to be comparable to the $\mathrm{U}_{3} \mathrm{Si}_{2}$ powder used as a reference (Figure $7 \mathrm{~A}$ and D) but differed significantly from the agglomerated crystallites seen in the arc melted materials.

Pressing was carried out with the same parameters as used for Pre-Melted and Co-Melted materials, but the produced green pellet was seen to be extremely friable in this case and became damaged from simple handling prior to sintering. 


\begin{tabular}{l|cc} 
Pellet & Geometric Density & Approx \% of Theoretical Density \\
\hline Co-Melt & $9.16 \mathrm{~g} / \mathrm{cm}^{3}$ & $75 \%$ \\
Pre-Melt & $10.15 \mathrm{~g} / \mathrm{cm}^{3}$ & $83 \%$ \\
\hline
\end{tabular}

Table 1: Densities of Pre-Melt and Co-Melt sintered pellets, compared to the theoretical $\mathrm{U}_{3} \mathrm{Si}_{2}$ density.

\subsection{Sintering}

Sintering was performed under a vaccuum of at least $2 \times 10^{-3}$ mbar throughout, and was performed in a graphite cruicible on tantalum chips, which were intended to act as an oxygen getter to limit material oxidation. Samples were heated to $1500^{\circ} \mathrm{C}$ at $20^{\circ} \mathrm{C} / \mathrm{min}$. Pellets were held at temperature for two hours and the furnace allowed to cool naturally from temperature following this period. A temperature below $1000^{\circ} \mathrm{C}$ was achieved within an hour of cooling. These parameters were selected due to their reported success in previous silicide manufactuing attempts [1].

\subsection{Sintered Material}

All sintered pellets were seen to show structural defects. The Powder Blended pellet was extremely brittle, and fractured into several pieces shortly after removal from the crucible. Both the Pre-Melt and Co-Melt pellets also showed significant cracks throughout.

Geometric densities are shown in Table 1 for Pre-Melt and Co-Melt materials, and are significantly below the calculated theoretical density. Geometric density could not be determined for the Co-Mixed pellet as it failed on removal from the crucible. Densities measured via helium pycnometry for the Co-Mixed pellet were close to $100 \%$ of theoretical density. Given the poor structural stability of this material this suggests a large volume of open porosity present.

Images of pellet microstructure for Pre-Melt and Co-Melted materials are shown in Figure 8, and images of Co-Milled material are shown in Figure 9. All materials have large amounts of porosity throughout the structure, which was most significant for the Powder Blended pellet, but also present in arc-melted samples. Pores within the Powder Blended sample are both larger and more numerous, as well as appearing to follow a different morphology to those within the melted samples. In all samples, pores have loose or partially sintered material within them, suggesting that they may result from a localised reduction in sintering rate, rather than gas evolution as seen in well-sintered ceramics. All three samples show a distribution of phases, with darker regions unconnected to porosity appearing throughout.

Figures 8 and 9 can be compared with Figure 10 which was produced using the same starting material and processing parameters to the arc melted material, but does not contain gadolinium. Porosity within the standard silicide is similar to that of the arc melted samples, and is likely a result of the milling parameters used which were optimised to break up and homogenise the gadolinium within the other samples. Silicde pellets are known to be sensitive to particle size distribution and further work would clearly be needed to optimise the overall process if gadolinium bearing pellets were of further interest [1].

Figure 12 A shows the distribution of uranium, gadolinium and silicon throguhout the premelted sample: areas of near-pure uranium-gadolinium remain from the as-melted material, and regions of a highly silicon-rich U-Si phase have formed (near $\mathrm{USi}_{2}$ ) which contains a small amount of gadolinium (1-2at\%). Figure 12 B shows that oxygen location closely mirrors that of the gadolinium, which also contains similar amounts of uranium in an approximately stoichiometric $(\mathrm{U}, \mathrm{Gd}) \mathrm{O}_{2}$. The source of this oxygen is potentially from the final polishing step which 


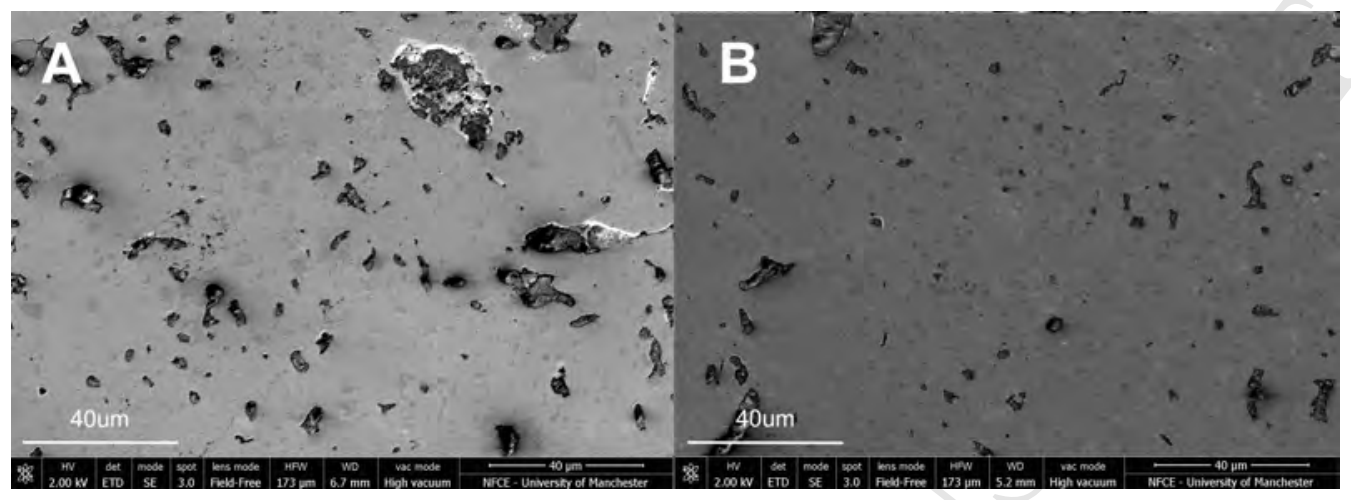

Figure 8: Microstructure of sintered pellets with material produced through arc melting. Co-Melt (A) and Pre-Melt (B) both show significant porosoity throughout as well as a multiple phases visible via density variations

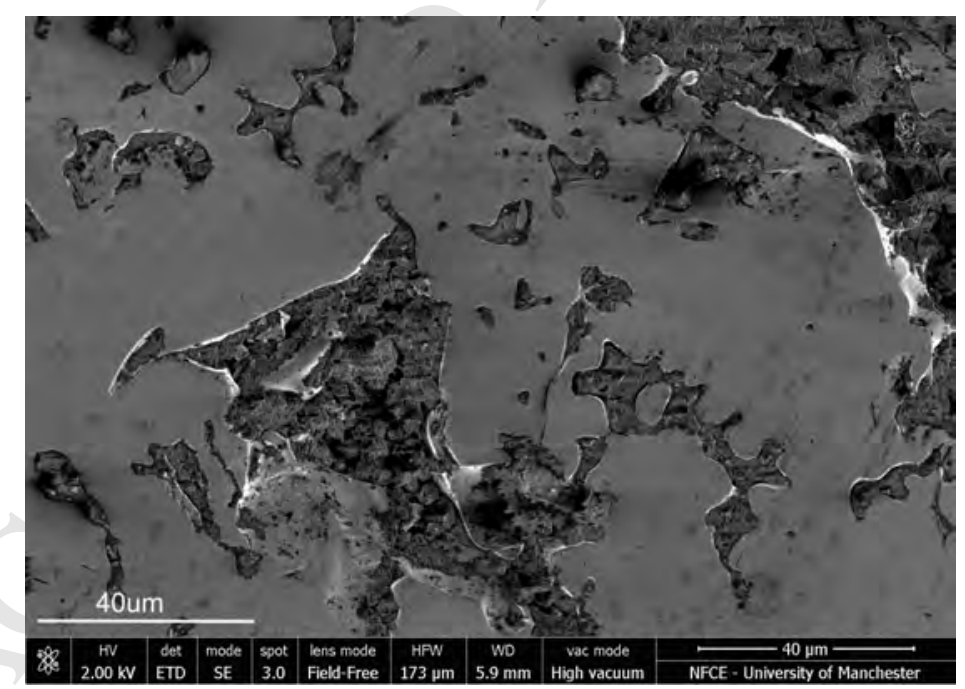

Figure 9: Electron microscopy images of sintered Powder Blended pellet. Pores in this pellet are large and irregular, and the material was seen to be extremely fragile during sample preparation 


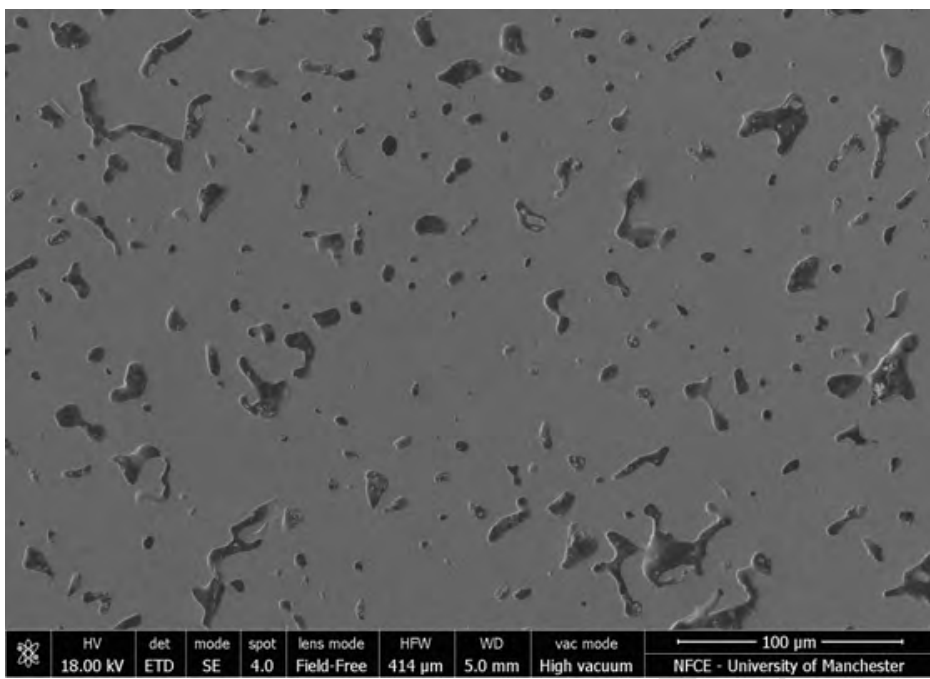

Figure 10: Electron microscopy image of $\mathrm{U}_{3} \mathrm{Si}_{2}$ pellet produced using same parameters as gadolinium bearing pellets within this study.

utilises colloidal silica. Although an alternative common source of oxygen in uranium silicide materials is the affinity for powdered material to bond with oxygen, both the high quality of the glove box atmosphere and the relatively short storage time of the material when powdered (less than 24 hours) makes this unlikely in this case. The distribution of elements within the Co-Melted sample was similar to that of the Pre-Melted material, although the silicon rich phase occurs in noticably smaller regions.

XRD of the arc melted sintered mateirals (Figure 13) showed that the $\mathrm{U}_{3} \mathrm{Si}_{2}$ structure had dissapeared almost entirely in both cases, and has been replaced with a $\mathrm{U}_{20} \mathrm{Si}_{16} \mathrm{C}_{3}$ structure reported previously by Noël et al [8]. This is broadly consistent with the EDX data reported here, as EDX is unable to distinguish between the single carbon peak which overlaps with a lowenergy uranium X-ray. As such, uranium analyses using EDX typically report carbon where none may be present, and it must be removed from the anaylsis to quantify uranium concentrations.

Examination of the Powder Blended material reveals a uniform uranium silicon matrix which is slighly uranium rich compared to $\mathrm{U}_{3} \mathrm{Si}_{2}$. As with melted material, XRD analysis of this sample (Figure 13) showed some carbon infiltration from the sintering process has occured, albeit greatly reduced from that seen in the melted samples and with significant $\mathrm{U}_{3} \mathrm{Si}_{2}$ remaining.

EDX of Powder Blended material suggests that gadolinium within the samples has largely remained within individual areas of the microstrucure, and some regions of oxide formation are visible within the gadolinium-rich areas (Figure 14). Unlike the arc melted material these regions do not contain significant concentrations of uranium. Similar oxide formation was observed on unpolished pellet fracture surfaces, suggesting this is a product of the sintering and/or postsintering storage process, rather than sample preparation. The oxygen observed in these regions is significantly more localised than that seen on the pre-pressed powders, and closely associated with the location of gadolinium precipitates. As there is no $\mathrm{UO}_{2}$ or $\mathrm{Gd}_{2} \mathrm{O}_{3}$ phase within the XRD of sintered material this suggests a rapidly formed surface layer on this phase, rather than bulk conversion of metal to oxide. It is however worth noting that these regions are significantly more 


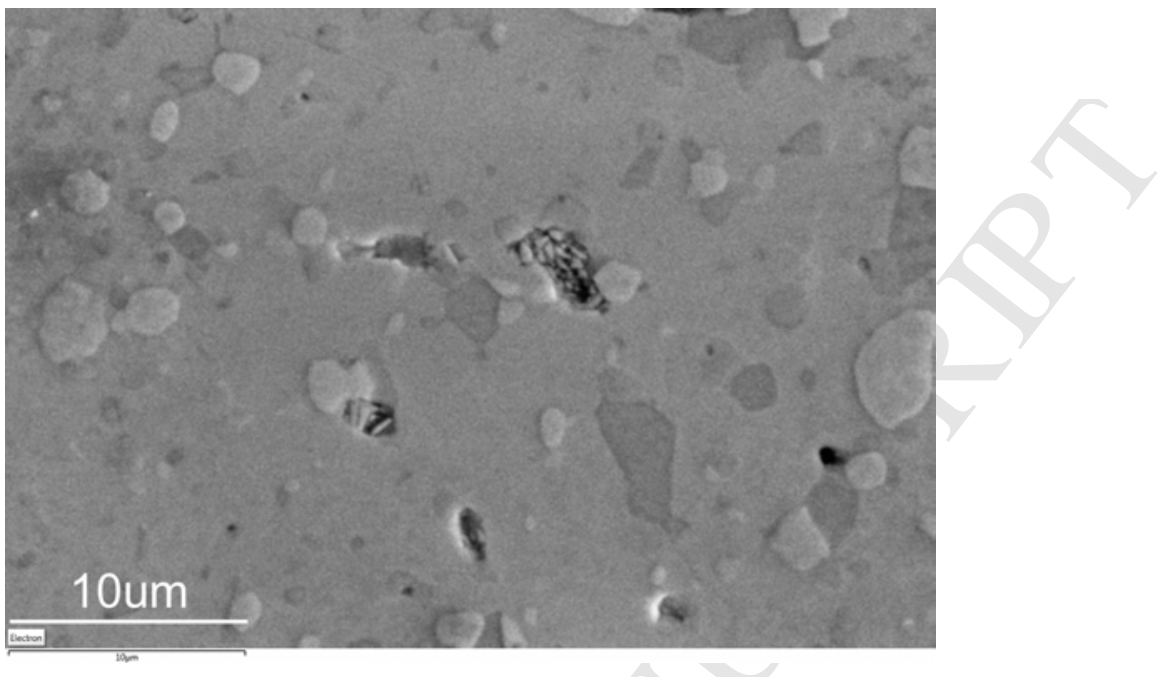

Figure 11: Electron image of sintered Pre-Melt material. Small spherical pores are visibile, as are three distinct phases
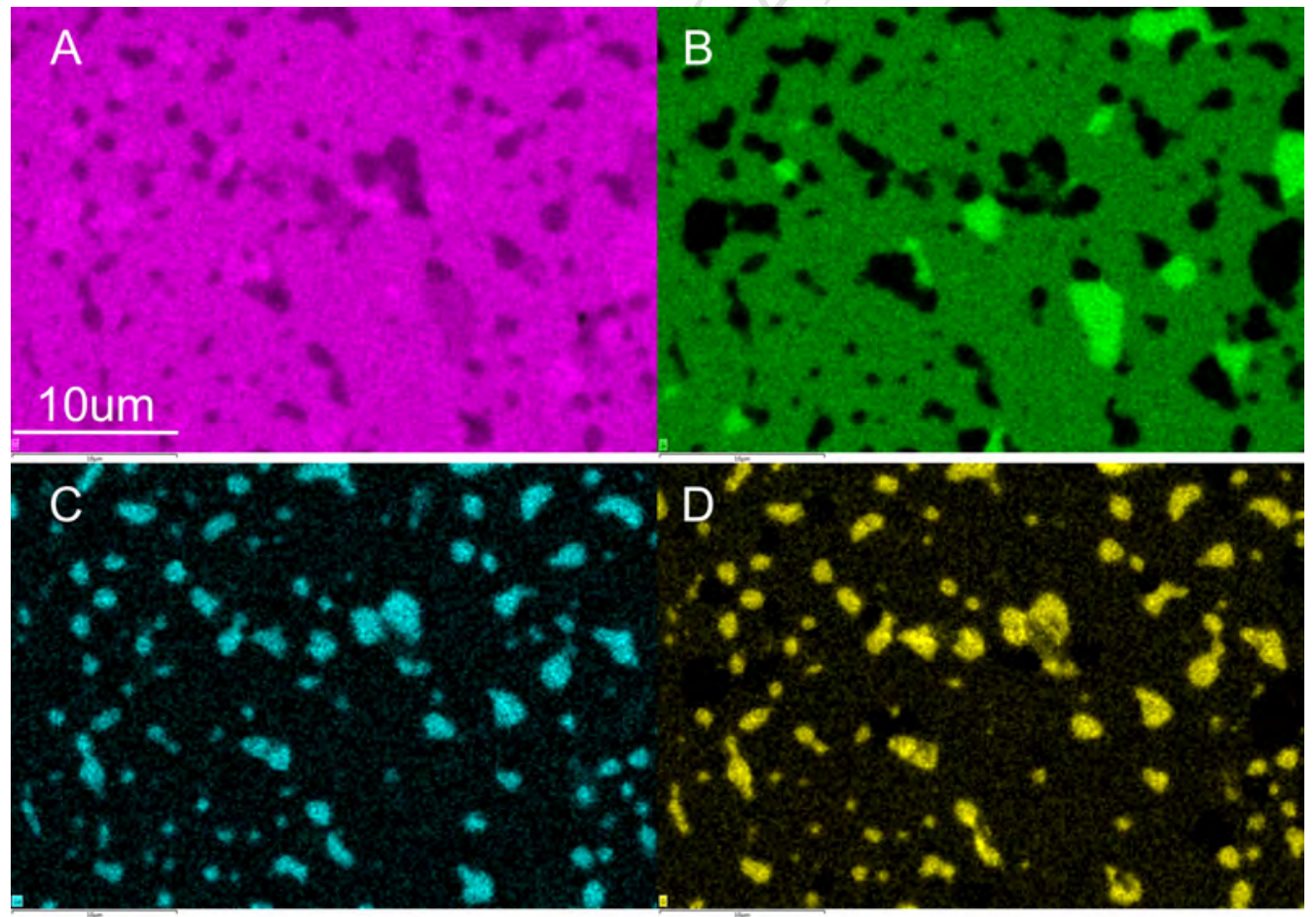

Figure 12: EDX of sintered Pre-Melt material. (U,Gd)O $\mathrm{O}_{2}$ has formed alongside U-Gd and silicon rich USi regions. A/pink - uranium, B/green - silicon, C/blue - gadolinium. D/yellow - oxygen 


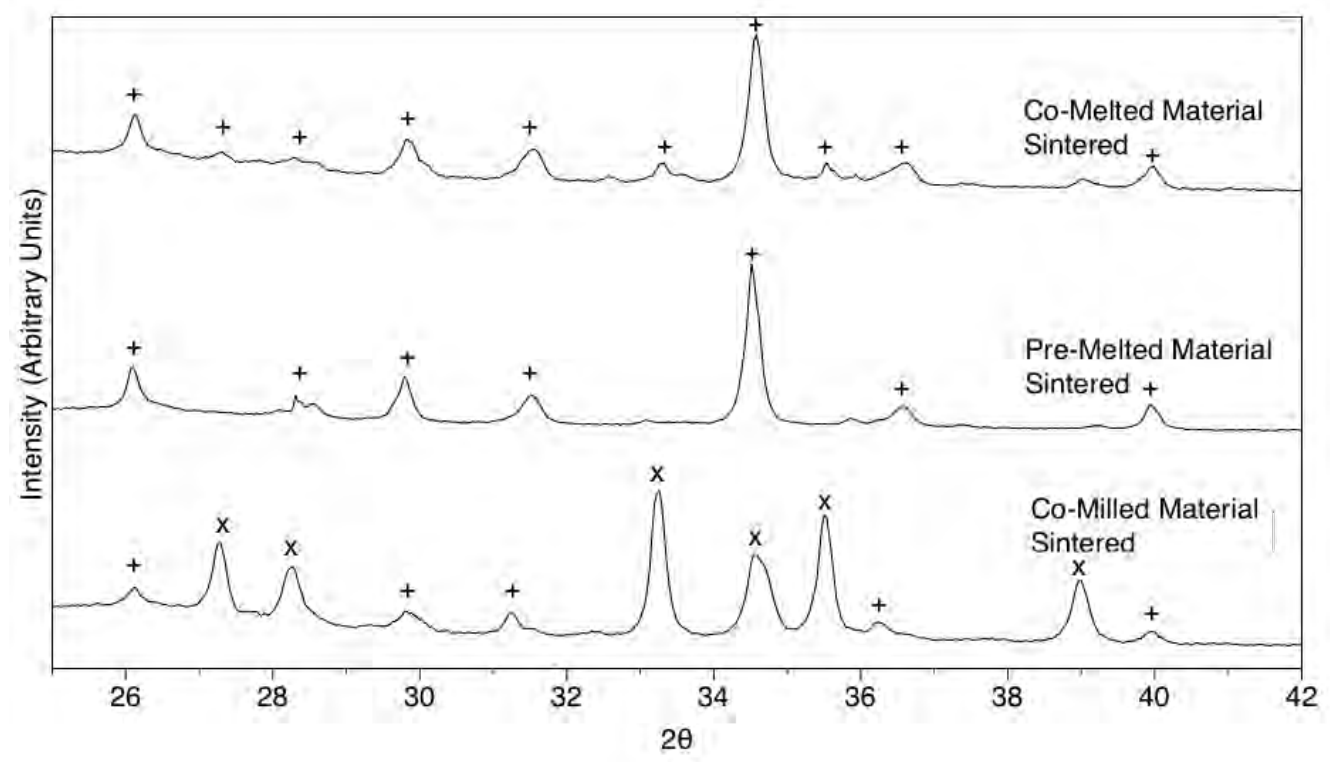

Figure 13: XRD Spectra of sintered materials. Both Pre-Melted and Co-Melted materials show the absence of the $\mathrm{U}_{3} \mathrm{Si}_{2}$ pattern (X), which has transitioned to $\mathrm{U}_{20} \mathrm{Si}_{16} \mathrm{C}_{3}(+)$ completely in both melted samples, and partially converted within the powder blended sample. Although both mateirals share several peaks, they can be distinguished by the relative peak intensities, particuarly of the peaks between $32^{\circ}$ and $37^{\circ}$.

oxidised than surrounding silicide regions.

\section{Discussion}

The manufacture of $\mathrm{U}_{3} \mathrm{Si}_{2}$ pellets containing significant quantities of gadolinium appears problematic. Arc melting produces an inhomogenous mixture of uranium metal, USi and $\mathrm{U}_{3} \mathrm{Si}_{2}$. Sintering leads to the formation of a ternary U-Si-C phase, most likely via an interaction with the graphtie crucible despite the use of tantalum chips separating the samples from the graphtie surface. Tantalum has been seen to be sufficient to both prevent the carbon interaction and act as an oxygen getter during $\mathrm{U}_{3} \mathrm{Si}_{2}$ manufacture with pellets produced alongside those discussed here, suggesting that the addition of gadolinium has greatly increased the reactivity of the material.

The formation of silicon-rich phases alongside uranium metal regions during arc melting likely rules out this techniuqe for the manufacture of $\mathrm{U}-\mathrm{Si}-\mathrm{Gd}$ materials, given the irradiation swelling behaviour known to ocurr in both USi and U. A basic study of the U-Si-Gd system using the MTDATA software from the UK National Physical Laboratory [9] suggests that as small amounts of $\mathrm{Gd}$ are added to $\mathrm{U}_{3} \mathrm{Si}_{2}$, gadolinium silicides begin to form preferentially, removing silicon from the uranium. ${ }^{1}$ This agrees reasonably well with these observations. Although pure gadolinium silicide regions are not observed via either method, silcion-rich USi regions do form initially, which contain a relatively small quantity of gadolinium. The formation of these silicon-rich regions during arc melting appears to lead to the creation of a U-Gd phase without

${ }^{1}$ With thanks to Prof Dave Goddard, UK National Nuclear Laboratory, for this analysis. 


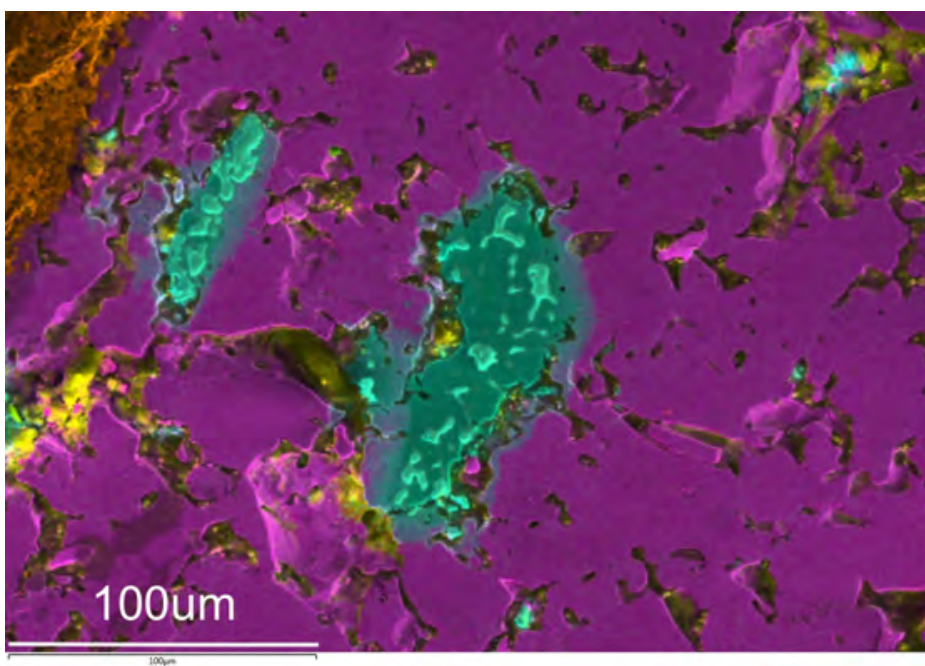

Figure 14: EDX of sintered Co-Milled material. Gadolinum remains concentrated into individual regions and has not dispersed throughout the pellet. Oxide formation is visible within the gadolinium rich areas. The silver in the top left is from the silver paint used to mount the sample. Pink $=\mathrm{U}$, Green $=\mathrm{Si}$, Blue $=\mathrm{Gd}$, Orange $=\mathrm{Ag}$, Yellow $=\mathrm{O}$

a distinct gadolinium silicide phase forming. Discrepancies between theoretical thermodynamic predictions and experimental observations are not unexpected in this case, as the Gd-Si phase diagram is relatively poorly understood compared to the uranium-gadolinium-oxygen system, and the U-Gd phase diagram does not yet exist in any meaningful way. Under sintering, a distinct uranium-gadolinium phase appears to have precipitated and subsequently rapidly oxidised.

During sintering, gadolinium appears to act as a strong catalyst for the formation of the $\mathrm{U}_{20} \mathrm{Si}_{16} \mathrm{C}_{3}$ phase throughout the pellet. Carbide formation on the surface of silicide pellets is known to occur, but is typically only a few microns thick and seen as a UC structure rather than a $\mathrm{U}-\mathrm{Si}-\mathrm{C}$ ternary. The formation of the ternary phase here is complete in both arc melted samples, where the gadolinium is relatively well dispered throughout the sample. It remains extensive in the powder blended sample where gadolinium is inhomogenously distributed.

While one solution to the problem of carbon infiltration witin U-Si-Gd pellets would be to sinter in an alternative furnace, this does not address the fundamental problem that the material appears to be extremely reactive, as evidenced by the thorough reaction with carbon and the rapid oxidation of gadolinium-uranium phases. Concerns already exist regarding $\mathrm{U}_{3} \mathrm{Si}_{2}$ oxidation behaviour, most notably that it is not a passive process, and the introduction of a more reactive phase is only likey to exacerbate the problem.

\section{Conclusions}

Pellets of gadolinium doped $\mathrm{U}_{3} \mathrm{Si}_{2}$ were manufactured to investigate its possible use as a burnable poison within an accident tolerant fuel system. The addition of gadolinium to $\mathrm{U}_{3} \mathrm{Si}_{2}$ results in the formation of a uranium-gadolinium metallic phase, and USi when produced via arc melting. When Gd-Si powder is blended with $\mathrm{U}_{3} \mathrm{Si}_{2}$ powders the results are more promising, but in all cases the resulting material was seen to be extremely reactive and formed a ternary U-Si-C 
phase. It is suggested that an alternative method of burnable poison introduction will be required for a future accident tolerant fuel system.

\section{Data Availability}

The raw/processed data required to reproduce these findings cannot be shared at this time as the data also forms part of an ongoing study.

[1] Jason M Harp, Rita E Hoggan, and Paul A Lessing. Uranium silicide pellet fabrication by powder metallurgy for accident tolerant fuel evaluation and irradiation. Journal of Nuclear Materials, 466:728-738, November 2015.

[2] V P Sinha, G P Mishra, S Pal, K B Khan, P V Hegde, and G J Prasad. Development of powder metallurgy technique for synthesis of U3Si2 dispersoid. Journal of Nuclear Materials, 383(1-2):196-200, December 2008.

[3] J T White, A T Nelson, Dunwoody J T, D D Byler, D J Safarik, and Kenneth J Mcclellan. Thermophysical properties of U3Si2 to 1773 K. Journal of Nuclear Materials, 464:275-280, September 2015.

[4] M R Finlay, G L Hofman, and J L Snelgrove. Irradiation behaviour of uranium silicide compounds. Journal of Nuclear Materials, 325(2-3):118-128, February 2004.

[5] Yinbin Miao, Jason Harp, Kun Mo, Sumit Bhattacharya, Peter Baldo, and Abdellatif M Yacout. Short Communication on "In-situ TEM ion irradiation investigations on U3Si2 at LWR temperatures". Journal of Nuclear Materials, 484:168-173, February 2017.

[6] K Hesketh. Burnable Poison-Doped Fuel. In Comprehensive Nuclear Materials.

[7] T B Massalski and H Okamoto. Binary Alloy Phase Diagrams, 1991.

[8] H Noël, S Chatain, T Alpettaz, C Guéneau, and C Duguay. Experimental determination of (U-Si-C) ternary phase diagram at $1000 \mathrm{C}$ and experimental points in the quaternary (U-Pu-Si-C) system. 2012.

[9] R H Davies, A T Dinsdale, J A Gisby, JAJ Robinson, and S M Martin. MTDATA - thermodynamic and phase equilibrium software from the national physical laboratory. Calphad, 26(2):229-271, June 2002. 